\title{
Skill in Epistemology II: Skill and Know how
}

\author{
Carlotta Pavese
}

\begin{abstract}
$\underline{\text { Abstract }}$
The prequel to this paper has discussed the relation between knowledge and skill and introduced the topic of the relationship between skill and know how. This sequel continues the discussion. First, I survey the recent debate on intellectualism about knowing how (\$1-3). Then, I tackle the question as to whether intellectualism (and antiintellectualism) about skill and intellectualism (and anti-intellectualism) about know how fall or stand together $(\$ 4-5)$.
\end{abstract}

\section{Intellectualism about know how: The linguistic controversy}

According to intellectualism about know how, a subject S's knowing how to $\Phi$, for some task $\Phi$, is a matter of S's knowing a true answer to the question "How could he himself $\Phi ? "$ An answer to such a question is of the form " $w$ is a way he himself could $\Phi$," for some way $w$ for S to $\Phi$. Accordingly, S's knowing how to $\Phi$ is a matter of S's knowing, for some way $w$ to $\Phi$, that $w$ is a way he himself could $\Phi$. Intellectualists add that such knowledge must be held "under a practical mode of presentation." To illustrate the need for such a qualification, suppose I look at a swimmer's swimming and my swimming instructor, pointing to the swimmer, says to me "That is a way in which you could swim too." I believe my instructor and what she said is in fact true. I may thereby come to know an answer to the question "How could I swim?" However, in the relevant sense, I may not have come to know how to swim. For one to come to know how to $\Phi$, in the relevant sense, it is for one to know an answer to the question "How could one oneself $\Phi ?$ ?" under a practical mode of presentation (Stanley \& Williamson, 2001; Pavese, 2015b).

Intellectualism was motivated initially (Stanley \& Williamson, 2001; Stanley, 2011) on the basis of linguistic arguments having to do with how know how is ascribed in English: superficially English know how ascriptions such as "Marie knows how to play the piano" seem to ascribe knowledge of an answer to the question How can she herself play the piano? for they appear to be of the form "S knows + (interrogative) how (de se) 
to $\Phi . " 1$

Such a linguistic motivation has been attacked on several fronts. Some have observed that know how is ascribed in different ways in different languages (Rumfitt, 2003; Roberts, 2009; Glick, 2009; Wiggins, 2012; Abbott, 2013; Ditter, 2015). In some languages, such as Italian and French, among others, know how ascriptions are of the form "S knows + bare infinitive" as in "Marie sait nager" and "Maria sa nuotare" (= "Mary knows to swim"). Italian and French ascribe know how through ascriptions embedding interrogatives ("S knows how to $\Phi$ ") but also through ascriptions embedding bare infinitivals ("S knows + (bare infinitive) to $\Phi$ " (= "S knows to $\Phi "))$ as in "Marie sait nager" and "Maria sa nuotare."

To this challenge, Stanley has responded that these ascriptions are to be analyzed as embedding an implicit interrogative - one where the question word "how" is not explicitly articulated (Stanley, 2011). However, Abbott and Ditter have observed that this response does not help with yet other languages, such as Russian, in which know how ascriptions - of the form "S (attitude verb) Vs + (infinitive) to $\Phi$ " - feature an embedding verb V ('umetj') that never licenses an interrogative complement nor a declarative complement (i.e., a that-clause) (Abbott, 2013; Ditter, 2016).

Let us try to get clear about what this cross-linguistic evidence really establishes. Consider the following linguistic argument for intellectualism. It has five premises. The first is that in English, know how ascriptions are univocally of the form "S knows + (interrogative) how to $\Phi "$ (Logical Form Premise). The second premise is that the relevant interpretation of the subject of the infinitival embedded clause is de se $(=S$ knows how he himself could $\Phi$ ) (Interpretation Premise). The next premise is that the best semantics for English ascriptions tells us that "S knows + (interrogative) how (de $s e)$ to $\Phi$ " is true just in case $\mathrm{S}$ knows a proposition that answers the question "How he himself could $\Phi "$ (Semantics for English Premise). ${ }^{2}$ Moreover, suppose that every know

\footnotetext{
${ }^{1}$ Knowing how ascriptions are ambiguous between a generic interpretation of the subject of the infinitival complement ("how to $\Phi "=$ how one could $\Phi$ ) and a de se interpretation ("how to $\Phi$ " = how oneself could $\Phi$ ). A further ambiguity has to do with whether the infinitival expresses an ability modal ("how to $\Phi$ " = how one could $\Phi$ ) or a deontic modal ("how to $\Phi "=$ how one should $\Phi$ ).

${ }^{2} \mathrm{I}$ am bracketing the important issue of whether de se content is really propositional (Lewis, 1979). By 'propositional', I will mean the kind of content knowledge of which can be ascribed through a know that
} 
how ascription in any language whatsoever can be translated into some English ascription of know how (The Expressive Power Premise) ${ }^{3}$ and (fifth premise) that the Disquotational Schema " "S" is true in L iff S" holds true. ${ }^{4}$ Now, let "S Vs $\Phi$ " be an ascription of know how in an arbitrary language $L$ that is correctly translated in English by "S knows + (interrogative) how (de se) to $\Phi$." Assuming that translation preserves at least truth conditions, The Expressive Power Premise guarantees that "S Vs $\Phi$ " be true in $L$ just in case "S knows + (interrogative) how (de se) to $\Phi$ " is true in English. By the Disquotational Schema, "S knows how to $\Phi$ " is true in English just in case S knows how to $\Phi$; so, we have that "S Vs $\Phi$ " is true in $L$ just in case $S$ knows how to $\Phi$. This conclusion, together with the Semantics for English Premise, the Logical Form Premise, and the Interpretation Premise, yields that "S Vs $\Phi$ " is true in $L$ just in case $S$ bears a knowledge relation towards an answer to the question "How he himself could $\Phi$." Through this argument, the truth conditions of any know how ascription, whether in English or in any other language, are still reduced to propositional knowledge, whether the relevant know how ascription has or not the interrogative form.

So, what is wrong, if anything, with this argument? People appealing to crosslinguistic evidence of the sort discussed may challenge the Logical Form Premise. They contend that the different ways of ascribing know how (through the infinitival form and through the interrogative form) in these languages indicate that know how ascriptions in English are ambiguous between two truth-conditionally not equivalent logical forms: an interrogative form and a bare infinitival form (Ambiguity Hypothesis) (Rumfitt, 2003; Wiggins, 2012; Ditter, 2016).

The main piece of evidence for the Ambiguity Hypothesis is that, in languages employing both the interrogative form and the infinitival form, those different ascriptions can come apart in their truth conditions. For example, it is claimed that the Italian sentence "Carlotta sa come nuotare" (interrogative form = "Carlotta knows how to

ascription. Because know-that ascriptions can report knowledge of de se content, my use of "propositional" is broad enough to include de se content.

${ }^{3}$ The Expressive Power Premise can be denied at the cost of accepting that there are ways in which one can have know how that cannot be expressed through a standard English ascription of know how - i.e., a rather unattractive consequence.

${ }^{4}$ At least if " $\mathrm{S}$ " does not contain indexicals. 
swim") may be true, while the sentence "Carlotta sa nuotare" (infinitival form = Carlotta knows to swim) is false, for example, if Carlotta lacks (in some sense) the ability to swim; similarly for its French translation.

Let us grant this is true. What would that establish? At most it establishes that the interrogative form in Italian and French has $a$ reading on which it has different truth conditions from the infinitival form. It does not establish that the interrogative form in those languages cannot also have another reading on which it has the same truth conditions as the infinitival form. Now, we already know that the interrogative form is susceptible of different interpretations, which depend on the interpretation of the subject of the infinitival complement: a generic interpretation ("how to $\phi$ " = how one could $\phi$ ) and a de se interpretation ("how to $\phi$ " = how oneself could $\phi$ ). ${ }^{5}$ And just like in English, in Italian and French, ascriptions embedding interrogatives can be used to express both the generic interpretation of the subject of the complement and the de se interpretation. For all the evidence provided thus far in favor of the Ambiguity Hypothesis, the interrogative form may come apart from the infinitival form only in its generic interpretation. In its de se reading, instead, it can still be truth conditionally equivalent to the infinitival form. And intellectualists have only ever claimed that the de se reading of the interrogative form - not the generic reading - is ability entailing (at least in Hawley's sense of counterfactual success (Hawley, 2003; Stanley, 2011; Pavese, 2015b; Beddor and Pavese, manuscript)).

If so, the available cross-linguistic evidence in French and Italian does not warrant postulating an ambiguity in the logical form of English know how ascriptions. Perhaps other languages besides French and Italian provide better evidence for the Ambiguity Hypothesis? Ditter has argued that in Russian, the interrogative construction must ascribe a different state from the 'umetj' ascription (+ infinitival), on the ground that one can coherently use in Russian sentences of the following form:

(1) John znaet kak igrat' na pianino, no on ne umeyet igrat.

\footnotetext{
5 A further ambiguity has to do with whether the infinitival expresses an ability modal ("how to $\phi$ " = how one could $\phi$ ) or a deontic modal ("how to $\phi "=$ how one should $\phi$ ).
} 
John knows + (interrogative) how to play the piano, but he does not know ('umetj') + (infinitival) to play the piano.

'John knows how to play the piano, but he doesn't know how to do it.'

But the same considerations made earlier apply here too. The fact that (1) is acceptable in Russian does not establish that the interrogative form in Russian cannot have also an interpretation on which it is truth conditionally equivalent to the Russian's infinitival form. As Ditter goes on to acknowledge, the only way to make (1) intelligible in English is to translate it as (2), where the generic interpretation of the first know how ascription and the de se interpretation of the second ascription are made explicit:

(2) One knows how one could play the piano but does not know how to play the piano himself.

So, here again, there is another explanation of the available cross-linguistic evidence that does not commit us to the Ambiguity Hypothesis. Just like English's ascriptions with that form, the interrogative form in Russian is ambiguous between a de se interpretation, on which it is truth conditionally equivalent to the infinitival form, and a generic interpretation of the subject of the infinitival embedded verb, on which it comes apart from the infinitival form. In (1), the presence of different constructions signals that the two constructions can be given different interpretations, and that suffices to rescue the sentence; by contrast, the following (3) sounds like a straight contradiction because (plausibly) there is a presumption of uniform interpretation for ascriptions looking/sounding superficially the same when they occur within the same discourse (Compare (3) and (4), where the ambiguous word "bank" is used twice (with no stress, focus, etc.). They are equally contradictory-sounding:

(3) Mary knows how to swim, but she does not know how to swim.

(4) Mary went to the bank this morning, but she did not go to the bank this morning.

)

In conclusion, the infinitival form and the interrogative form may well come apart 
in their truth conditions; but that is compatible with the interrogative form's having one reading (the de se reading) on which it is truth conditionally equivalent to the infinitival form; and so, it is also compatible with the claim that in English know how ascriptions univocally have the interrogative form (although they are semantically ambiguous between the generic and the de se interpretation of the subject of the infinitival embedded verb).

Let me mention two independent reasons to doubt the Ambiguity Hypothesis. Suppose English know how ascriptions were indeed ambiguous between two different syntactic constructions. What syntactic constructions would English know how ascriptions be ambiguous between? The supporters of the Ambiguity Hypothesis rarely engage with this issue but, presumably, these ascriptions would have to be ambiguous between the form "s knows + (interrogative) how to $\phi$ " and the form "s knows + how + (infinitival) to $\phi . "$ Now, if "s knows how to $\phi$ " could have the logical form "s knows + how + (infinitival) to $\phi$," it would make for quite an unprecedented construction, one where the adverbial phrase "how" intervenes between "know" and the bare infinitive "to $\phi . "$ Observe that no other adverbial phrases is ever allowed in that position:

(5) a. Mary knows to swim.

b. ?? Mary knows quickly to swim;

c. ?? Mary has come to know effortlessly to swim.

d. ?? Mary has come to know willingly to swim.

e. ?? Mary knows however to swim.

Finally, it should be pointed out that, although in Italian and French both the infinitival form and the interrogative form are usually available, with some embedded verbs, the infinitival construction is infelicitous and only the interrogative construction is allowed:

(6) A. \#Mary sa prendere suo padre.

Mary knows to-deal-with her father.

Mary sa come prendere suo padre. 
'Mary knows how to treat her father'.

(7) \#Mary sa trattare i suoi colleghi.

Mary knows to-treat her colleagues.

Mary sa come trattare i suoi colleghi.

'Mary knows how to treat her colleagues'.

(8) \#Mary sait traiter son clients.

Mary knows to-treat her clients.

Mary sait comment traiter son clients.

'Mary knows how to treat her clients.'

In these examples, the infinitival form is out (i.e., if used, it would ascribe a different sort of know how from that ascribed by the correspondent interrogative form. For example, (1)-A would ascribe to Mary knowledge how to grasp her father as opposed to knowledge how to deal with him). There are then two possibilities: either no genuine know how is, or can be, ascribed in all of those cases, for the infinitival form is out; or in those cases, the interrogative form replaces the infinitival form for all the intents and purposes. The latter option seems much more plausible. But if so, then in those languages too, the interrogative form must have a reading (plausibly the de se reading of the subject of the embedded verb) on which it can be truth conditionally equivalent to the infinitival form.

So much for the ambiguity hypothesis. Others have challenged the Semantics for English Premise (Abbott, 2003; Roberts, 2009; Brogaard, 2011; Michaelis, 2011; Bengson \& Moffett, 2011; Ginzburg, 2011). These challenges would deserve more discussion than I can provide here. Let me just briefly consider Bengson and Moffett's, who have argued that the complement of know how ascriptions ("how to $\Phi$ ") is not an interrogative but an "objectual” complement (Bengson \& Moffett, 2011). They argue that "knowing how to $\Phi$ " is equivalent to "knowing a way to $\Phi$ " in pretty much every context. On this basis, they claim that ascriptions of know how ascribe knowledge (or understanding) of a way to $\Phi$ rather than knowledge of a proposition. 
However, this alternative semantic proposal faces some serious problems. To mention just one, certain verbs akin to "know," such as "learn," cannot systematically embed objectual complements. To illustrate, whereas the sentence "Marco knows the capital of Italy" is ambiguous between the objectual interpretation (Marco knows Rome) and the non-objectual interpretation (Marco knows what the capital of Italy is), the sentence "I learned the capital of Italy" cannot mean the same as "I learned Rome." It can only mean that I learned what the capital of Italy is. So, it is very unlikely that "learn"ascriptions embedding nominal complements (such as "the capital of Italy") ever license an objectual interpretation. And yet one certainly comes to know how to $\Phi$ by learning how to $\Phi$. (Similar considerations hold for verbs such as "tell" or "find out" (Nathan, 2006; Cumming, 2008). $)^{6}$

As of now, the linguistic controversy between objectualists and intellectualists is not settled. Because the best case for intellectualism about know how is actually not linguistic, I will now put the linguistic controversy to one side and look at stronger philosophical motivations on behalf of this view.

\section{Intellectualism about know how: The non-linguistic motivation}

Abilities and know how can come apart. For example, one may have the ability to perform a semaphore version of "Grey's Elegy" in virtue of having the ability to execute a series of movements that coincides with that semaphore version of Grey's Elegy. Plausibly, however, one does not know how to perform a semaphore version of Grey's Elegy if one cannot identify that series of movements as identical to that semaphore version (Carr, 1979). Hence, knowing how to perform an action $\Phi$ plausibly requires one to be able to identify certain circumstances as ones that are adequate for $\Phi$-ing. Carr concluded that, whereas abilities can be extensional, know how ascriptions create intensional contexts.

Moreover, all sides of the dispute agree that knowing how to $\Phi$ requires not just ability to $\Phi$ but the ability to intentionally $\Phi$ (Hawley, 2003; Setiya, 2011; Pavese, 2015a; Pavese, 2015b). And ascriptions of the ability to intentionally $\Phi$, just like know how

\footnotetext{
${ }^{6}$ For criticisms along these lines, see Pavese (manuscript, "Know how and Gradability"). See also Habgood-Coote (manuscript, "Knowledge-how: Interrogatives and Free Relatives").
} 
ascriptions, are intensional. Suppose then knowing how to $\Phi$ does require the ability to intentionally perform $\Phi$. If so, whether know how requires a propositional attitude depends on whether one can intentionally $\Phi$ without having a propositional attitude about how to $\Phi$. But according to many influential views of intentional action, intentionally $\Phi$ ing requires having a belief about how to $\Phi$ : in particular, it requires having an action plan, which is characterizable in terms of a belief about how to perform $\Phi$ for it requires believing that it is at least likely for one's action to result in successfully $\Phi$-ing. (See, for example, Goldman 1970; Mele \& Moser, 1994; Gibbons, 2001). On these bases, some intellectualists have argued that know how requires a propositional attitude (Pavese, 2015b; Pavese, forthcoming; Valaris, manuscript).

Could not the ability to intentionally $\Phi$ be explained in terms of a nonpropositional state, such as objectual understanding of a rule to $\Phi ?^{7}$ Consider the example of Miriam who, exceptionally gifted at manipulating numbers and blind since birth, has never heard of chess. Suppose Miriam now learns certain rules that are the algebraic translations of the rules for chess and thereby she acquires the ability to follow such rules. As she reacquires her sight, presented with an object, that unbeknownst to her is a chessboard, Miriam maps the algebraic rules into the chessboard pieces according to two different mappings, mapping '(Chess)', corresponding to the game of chess, and mapping '(Chess*)', where the role of the king and of the queen are inverted. In this circumstance, Miriam plausibly does not have the ability to intentionally play what is in fact a game of chess and so she does not know how to play chess, unless she is told which set of rules she should employ in a game of chess. Note further that Miriam may understand each set of rules perfectly well and still not know how to play the game when presented with a chessboard, until she learns which rules are the rules to play chess (Pavese, 2015a).

This argument purports to show that a propositional attitude about how to perform a task is required for intentional action. But is propositional knowledge of means to ends required for intentional action, over and above true belief? Gibbons argues that one cannot plausibly win the lottery intentionally, nor can one intentionally defuse a bomb if

\footnotetext{
${ }^{7}$ See Bengson \& Moffett, 2011.
} 
one unintentionally and fortuitously chooses the correct wire; and that in both cases, a plausible explanation for the lack of intentionality is that the subjects could not know, for some way to win the lottery (or for some way to defuse the bomb), that $w$ is a way to win the lottery (or a way to defuse the bomb) (Gibbons, 2001). Some disagree, however, as to whether the actions count as unintentional in these cases and as whether other explanations of the cases are available. ${ }^{8}$ This is another juncture at which the debate is still early and the actual promise of these new arguments in favor of intellectualism is still to be carefully assessed.

\section{Arguments against intellectualism about know how}

The view that intentional action requires a propositional attitude has been challenged for the particular case of basic actions (Setiya, 2011). Setiya observes that one can perform a basic action of clenching one's fist without even having the belief that one can succeed at doing it. Suppose for example that one had undergone an injury and did not believe that one had healed.

A possible reply is that such an action would plausibly count as intentional only provided that the subject had a non-zero credence of success. And arguably, credences of this sort can be knowledge too, albeit of a probabilistic sort (Moss, 2013). Another line of response to Setiya consists in emphasizing that if intentionality and planning are supposed to go together and if basic action is supposed to play a role in planning, then a basic action must require the relevant belief, for one could not plan anything starting from that action unless one believed that one could perform it (Pavese, forthcoming).

According to the gradability objection, know how cannot be identical to propositional knowledge, for whereas the latter is absolute, the former can come in degrees (Ryle, 1949; Bengson \& Moffett, 2011; Wiggins, 2012). Intellectualists have responded that the relevant gradability is gradability of the ascriptions of knowing how and, as such, in the first instance a linguistic phenomenon, one compatible with the relevant knowledge state ascribed being absolute. Accordingly, when we say that one knows how to swim to some extent, what we say is true just in case one knows some extent of a practical answer; and when we say that Serena knows how to play tennis

\footnotetext{
${ }^{8}$ For dissenting voices on this point, see (Cath, 2011; Setiya, 2011).
} 
better than Pennetta, what we say is true just in case she knows better practical answers to the question "How could one play tennis?" (Pavese, manuscript).

Another important objection against intellectualism about knowing how has centered on the epistemic profile of know how (Cath, 2011; Cath, 2014; Poston, 2009; Carter \& Pritchard, forthcoming). (Cath, 2011) observes that I may learn from a manual how to fix a light bulb and come on those bases to know how to fix a light bulb, even though the manual was given to me with the intention to mislead me and its instructions were only accidentally correct. It seems that in this case I may know how to fix a light bulb without knowing any of the relevant instructions, for I have been gettiered. So, the argument goes, know how cannot possibly require more than true belief.

However, recently this diagnosis of Cath's examples has been challenged. For example, Marley-Payne (manuscript) observes that it is not permissible to conjoin one know how ascription with the denial of a correspondent know that ascription, as evidenced by the fact that sentences such as (9) are borderline incoherent: ${ }^{10}$

(9) Mark knows how to fix a light bulb but does not know that the first step to fix it is to get a new light bulb and unscrew the old one.

This fact is hard to explain on a view on which know how does not require knowledge of means to ends in addition to true belief.

Some have pointed out that mere possession of information (or knowledge) cannot suffice for know how (Fridland, 2013; Fridland, 2014), for intelligent selection of means to ends is also required. Intellectualists may reply that it is the knowledge state that accounts for such an intelligent selection: as Stalnaker observes, knowledge possession is not simply a matter of having acquired a certain amount of information through the right process - it is also being able to use information intelligently and relevantly for the purpose of guiding action (Stalnaker, 2012).

As we have seen, intellectualists identify knowing how with knowing that a particular way is a way to $\mathrm{F}$ under a practical mode of presentation. But many have

\footnotetext{
${ }^{9}$ Pavese (manuscript, "Know how and Gradability").

${ }^{10}$ Marley-Payne (manuscript, "Know how and Gettier. The plot thickens").
} 
observed that the notion of practical mode of presentation is mysterious and in need of elucidation (Glick, 2013; Noë, 2005; Stalnaker, 2012). In response, Pavese has developed a Fregean notion of practical modes of presentation - as practical senses - and has argued that examples of practical senses can be found in operational semantic values for programming languages (Pavese, 2015b). ${ }^{11}$

Finally, some have observed that know how may differ from propositional knowledge in that, whereas the latter plausibly entails belief, know how does not (Wallis, 2008; Brownstein \& Michaelson, 2015). For example, studies show that when catching a ball, ball players make anticipatory saccades to shift their gaze ahead of the ball one or more times during the course of its fight towards them. These players know how to catch a ball, and their way of catching a ball requires making anticipatory saccades when watching the ball as it falls, but the players do not believe that making anticipatory saccades is part of how they catch the ball. Rather they believe that they are tracking the ball the whole time.

The intellectualist can reply that, from the fact that the subject has false beliefs about how she catches the ball, it does not follow that the subject does not also have correct beliefs about it. After all, one may have plenty of false beliefs about Ortcutt (that he is an honest man, that does not wear hats, etc.) and at the same time have one true belief about him under the perceptual mode of presentation (i.e., that that man is a spy). So, a natural response is that there is some sense in which the player correctly believes that his manner of tracking the ball has a chance of resulting in success. One way of developing this natural response is to appeal to a picture of our belief box as "fragmented" or "compartmentalized" (Lewis, 1982; Stalnaker, 1984; Greco, 2015) - a model of our doxastic life that is independently motivated. ${ }^{12}$ In further defense of this strategy, an intellectualist may appeal, once again, to prominent theories of intentional action (Goldman, 1970; Gibbons, 2001; Mele \& Moser, 1994) that do motivate the

\footnotetext{
${ }^{11}$ Others have developed a more Russellian view of practical modes of presentation (Bianchi, manuscript, "Know how and Information Access").

${ }^{12}$ One reason adduced is that the subjects do not seem to be irrational (Brownstein \& Michaelson, 2015, pp. 14-16) and cases of fragmentation are cases of irrationality, and the subjects in their examples are not irrational. But, actually, fragmentation is particularly plausible for subjects that undergo Frege's puzzle, and it would be bizarre to deem such subjects irrational (Elga \& Rayo, manuscript, "Fragmentation and Access").
} 
positing of the relevant belief so as to explain the intentionality of the relevant know how's manifestation.

\section{From intellectualism about know how to Intellectualism about skill}

What is the relationship between intellectualism (or anti-intellectualism) about skill and intellectualism (or anti-intellectualism) about know how? In the prequel to this essay, we observed that it is a platitude that, if one is skilled at $\Phi$-ing, or has the skill to $\Phi$, then one must know how to $\Phi$ :

(2a) If $S$ is skilled at $\Phi$-ing, then $S$ knows how to $\Phi$.

(2b) If $S$ has the skill to $\Phi$, then $S$ knows how to $\Phi$.

Moreover, I provided an argument to the effect that, while knowing how to perform a task does not entail being skilled at it, knowing how to perform a task sufficiently well does entail it. ${ }^{13}$ That gives us the following bi-conditionals:

(3a) S knows how to $\Phi$ if and only if S has the skill to $\Phi$.

(3b) S knows how to $\Phi$ sufficiently well if and only if S is skilled at $\Phi$-ing.

(3a) and (3b) together with intellectualism about knowing how entail intellectualism about skill.

Suppose one defends the view that skill is not the same as a standing propositional knowledge state but rather is a disposition to know, as argued by Stanley and Williamson (Stanley \& Williamson, 2016). Because Stanley and Williamson also endorse intellectualism about knowing how (Stanley \& Williamson, 2001; Stanley, 2011), they have to give up the platitudinous (2a) (or 2b). Moreover, barring an argument for the value of know how over and above the value of skill, this view downsizes the importance of know how (as well as of intellectualism about knowing how) for a view of intelligent action, for all the interesting work in explaining intelligent action is done by skill rather

\footnotetext{
${ }^{13}$ One might object that whereas know how does not entail ability, skill does. So one can know how to $\Phi$, without having the skill to $\Phi$, if one happens to lack the relevant ability. Some intellectualists deny that know how entails ability (Ginet, 1975; Stanley \& Williamson, 2001), on the grounds that one may know how to perform a task but be unable to perform it, for example, the pianist who has lost her arms in a car accident. But just as it is important to distinguish between knowing how to perform a task and being (actually and circumstantially) able to perform it (Hawley, 2003), it is important to distinguish between having a skill to perform a task and being (actually and circumstantially) able to perform it (see Noë, 2005; Glick, 2011). Recently intellectualists have tried to account for the intuitive entailment from know how to ability (Pavese, 2015b; Bianchi, manuscript, "Know how and Information Access").
} 
than by know how.

The proponents of a view that identifies skills with dispositions to know may cling to both $(2 a) /(2 b)$ and $(3 a) /(3 b)$ by taking know how itself to be a disposition to know rather than a standing propositional knowledge state. This view of know how is not entirely unmotivated. For example, consider the ascription "Mary knows how to deal with kids." In some uses of this ascription, what we are saying is that in most circumstances involving kids, Mary knows how to deal with kids in those circumstances. By quantifying in this way over circumstances, we do not seem to ascribe to Mary $a$ standing knowledge state (standing across different circumstances). For there seems to be a use of the ascription in which it may be true even though Mary does not know a general answer to the question "How could she deal with kids in every circumstance?" In that use, we seem to be ascribing to Mary a disposition to come to know, in different circumstances $c$, the answer to the question "How could she deal with kids in $c$ ?"

Alternatively, one could argue against $(2 a) /(2 b)$ that there are sorts of skills that cannot plausibly amount to know how. For example, one might contend that abilities that are usually called "perceptual skills" are not examples of knowing how, as it does not make sense to say that one knows how to see, or knows how to perceive. ${ }^{14}$

On some widely shared assumptions about the nature of skills, however, one might question whether the perceptual case really constitutes a counterexample to $(2 \mathrm{a}) /(2 \mathrm{~b})$. Many talk about skills to refer to sorts of abilities that $(i)$ are acquirable and (ii) that manifest characteristically in actions, for one is skilled at doing things and doings are actions (Ryle, 1949; Stanley, 2011; Dickie, 2012; Fridland, 2014). On this understanding of skill, then not every perceptual ability will count as a skill. For example, consider the ability that, according to Marr's computational sub-personal account of early vision, the primal sketch possesses to detect changes in the reflectance of physical surfaces (Marr, 1982). Such a perceptual ability is not acquirable nor characteristically manifests through actions - for detecting changes in the reflectance of physical surfaces is not something that a subject can intentionally do or abstain from doing (Pavese, 2015b, p. 14). On the other end of the spectrum, consider cases of expert perception, such as chicken sexers

\footnotetext{
${ }^{14}$ This assumes an Anscombian constraint on intentional action, according to which one can intentionally $\Phi$ only one has non-inferential knowledge that one is $\Phi$-ing when one does (Anscombe, 1963).
} 
and bird watchers. In these cases, it is plausible that the relevant perceptual ability does characteristically manifest through acts - for example, the chicken-sexers manifest their skill by intentionally directing their attention to the features of the chickens that are indicative of their sex..$^{15}$ But these examples of are also plausibly examples of knowing how - as the chicken sexers surely know how to chicken sex. ${ }^{16}$

Finally, consider the example of somebody who can reliably make babies stop crying, even though every time one does it, one has no idea whether or how one is doing it. Is this an example of skill? Some want to draw the further distinction between a knack and a skill. The distinction first appeared in Plato. ${ }^{17}$ In Plato, the distinction was between a natural aptitude (or propensity) on one hand and an ability that is acquired through training and practice on the other. Only the latter qualifies as a skill. A further feature of the distinction is that, while skills and knowing how manifest in acts, knacks primarily manifest through tryings or attempts (Pavese, 2013). Accordingly, one may have a knack for babysitting and succeed at doing so quite reliably without knowing how to do it.

\section{Conclusions}

After surveying the recent literature on intellectualism about know how, I have put forward an argument for thinking that intellectualism about know how entails intellectualism about skill and looked at some possible objections. Let me end with a final observation. Our ordinary usage of the English word "skill" is quite liberal and plausibly encompasses both instances of know how, on one hand, and of talents or knacks. But an important question to ask is whether this liberal sense of "skill" corresponds to a natural kind or to a disjunctive one. ${ }^{18} \mathrm{~A}$ third possibility is that we are dealing with more than one natural kind - one corresponding to the liberal sense of "skill," and the other corresponding to Ryle's notion of skill as well as to the ancients' notion of techne - each important on its own and worthy of philosophical investigation.

\footnotetext{
15 Moreover, studies show that chicken sexing abilities and bird watchers abilities are acquirable only through a lot of training and practice (Pylyshyn, 1999).

${ }^{16}$ Lewis famously uses as a paradigmatic example of know how the perceptual case of knowing how to recognize the locomotive C-38 by sight (Lewis, 1988).

${ }^{17}$ See Plato, 1961, Gorgias. 461b3, 464b-465d.

18 The previously observed fact that certain languages (such as French and Italian) do not even have a designated word for this liberal sense of "skill" may suggest that no natural kind corresponds to such a liberal use of the English word.
} 
An answer to these questions may require a more sophisticated taxonomy of cognitive and non-cognitive abilities that is available at present, one based not just on our ordinary usage of the word "skill" but also informed by the recent advances in cognitive psychology and in cognitive neuroscience.

\section{$\underline{\text { References }}$}

Abbott, B. (2013), Linguistic Solutions to Philosophical Problems: the case of knowing how. Philosophical Perspectives, 27: 1-21. doi:10.1111/phpe.12019

Anscombe G. E. M. 1963. Intention. Blackwell, Oxford.

Bengson J, Moffett M. 2011. Non-Propositional Intellectualism. In Bengson, Moffett (eds), Knowing How: Essays on Knowledge, Mind, and Action (Oxford: Oxford University Press): 161-195.

Brogaard B. 2011. Knowledge-How: A Unified Account, Knowing How: Essays on Knowledge, Mind, and Action, J. Bengson and M. Moffett eds., Oxford: Oxford University Press (2011): 136-160.

Brownstein M, Michaelson E. 2015. Doing without believing: Intellectualism, knowledge-how, and belief-attribution. Synthese. Online first advance access: 1-22. DOI 10.1007/s11229-015-0888-9

Carr D. 1979. The logic of knowing how and ability. Mind 88: 394-409.

Carter A, Pritchard D. forthcoming. Knowledge-how and epistemic luck. Nous.

Cath Y. 2011. Knowing how without knowing that. In Bengson, Moffett (eds.), Knowing How: Essays on Knowledge, Mind and Action. Oxford University Press, Oxford: 113135.

Cath Y. 2015. Revisionary intellectualism and Gettier. Philosophical Studies 172(1): 727. DOI: $10.1007 . s 11098-013-0263-y$

Cumming S. 2008. Variabilism. The Philosophical Review, 117(4):525-554.

Ditter A. 2015. Why Intellectualism still fails. The Philosophical Quarterly. Online first advance access: 1-16. DOI: 10.1093/pq/pqv115

Fridland E. 2013. Problems with Intellectualism. Philosophical studies 165(3): 879- 891. DOI: $10.1007 . s 11098-012-9994-4$

Fridland E. 2014. They've lost control: Reflections on Skill. Synthese 191(12): 2729- 
2750. DOI: $10.1007 / \mathrm{s} 11229-014-0411-8$

Gibbons J. 2001. Knowledge in action. Philosophy and Phenomenological Research 62(3): 579-600. DOI: 10.1111/j.1933-1592.2001.tb00075.x

Ginzburg, Jonathan. 2011. How to resolve how to. Knowing How: Essays on Knowledge, Mind, and Action: 1-36.

Glick E. 2012 Ability and Knowledge Attributions. In Knowledge Attributions, eds. Jessica Brown and Mikkel Gerken, Oxford University Press, 120-139.

Glick E. 2013. Practical Modes of Presentation. Nous 49(3): 1-22. DOI: 10.1111.nous.12052

Goldman A. 1970. A Theory of Human Action. Prentice Hall, Englewood Cliffs, New Jersey.

Greco D. 2015. Iteration and fragmentation. Philosophy and Phenomenological Research 91.3: 656-673. DOI: 10.1111/phpr.12086

Hawley K. 2003. Success and Knowledge How. American Philosophical Quarterly 40(1): 19-31.

Lewis D. 1979. Attitudes de dicto and de se. The Philosophical Review 88.4 (1979): 513543. DOI: $10.2307 / 2184843$

Lewis D. 1988. What experience teaches. In Lewis D. Papers in Metaphysics and Epistemology (Cambridge: Cambridge University Press, 1999): 262-90.

Marr D. 1982. Vision: A Computational Investigation into the Human Representation and Processing of Visual Information. New York: Henry Holt and Co.

Mele A, Moser P. 1994. Intentional action. Nous 28: 39-48. DOI: 10.2307/2215919

Michaelis, Laura A. 2011. Knowledge Ascription by Grammatical Construction. In J. Bengson and M. Moffett, (eds.), Knowing How: Essays on Knowledge, Mind, and Action. Oxford: Oxford University Press. 261-279.

Moss S. 2013. Epistemology formalized. Philosophical Review 122(1): 1-43. DOI: $10.1215 / 00318108-1728705$

Nathan L. E. 2006. On the interpretation of concealed questions. $\mathrm{PhD}$ thesis, Massachusetts Institute of Technology.

Noë A. 2005. Anti-Intellectualism. Analysis 65(288): 278-90. DOI: 10.1093/analys/65.4.278 
Pavese C. 2013. The Unity and Scope of Knowledge. Ph.D. Dissertation Rutgers University.

Pavese C. 2015a. Knowing a Rule. Philosophical Issues. A Supplement to Nous, 25(1): 165-188. DOI: 10.1111/phis.12045

Pavese C. 2015b. Practical senses. Philosophers' Imprint, 15(29): 1-25.

Pavese C. forthcoming. Know how, Intentions, and Abilities. Synthese.

Plato 1961. The collected dialogues of Plato, Cooper, Lain, Hamilton, Cairns, et al. (eds.), Volume 71, Princeton University Press, Princeton 1961.

Pylyshyn Z. 1999. Is vision continuous with cognition? The case for cognitive impenetrability of visual perception. Behavioral and brain sciences 22.03: 341-365.

Poston T. 2009. Know how to be gettiered? Philosophy and Phenomenological Research 79(3): 743-747. DOI: 10.1111/j.1933-1592.2009.00301.x

Roberts C. 2009. Know-how: A compositional approach. Theory and evidence in, Edie Tor and Ed Itor (eds.), CSLI Publications, pp. 1-31.

Rumfitt I. 2003. Savoir faire. Journal of Philosophy. 100: 158-166. DOI: 10.5840/jphil2003100319

Ryle G. 1949. The Concept of Mind. Chicago University Press, Chicago.

Setiya K. 2011. Knowing how. Proceedings of the Aristotelian Society 112(3): 285-307.

DOI: $10.1111 /$ j.1467-9264.2012.00336.x

Snowdon P. 2004. Knowing How and Knowing That: A Distinction Reconsidered. Proceedings of the Aristotelian Society 104(1): 1-29. DOI: 10.1111/j.00667373.2004.00079.x

Stalnaker R. 1984. Inquiry. Cambridge University Press.

Stalnaker R. 2012. Intellectualism and The Objects of Knowledge. Philosophy and Phenomenological Research 85(3): 753-761. DOI: 10.1111/j.1933-1592.2012.00640.x

Stanley J. 2011. Know How. Oxford University Press, Oxford.

Stanley J, Williamson T. 2001. Knowing How. Journal of Philosophy 98 (8): 411-444. DOI: $10.2307 / 2678403$

Stanley J, Williamson T. 2016 Skill. Nous Online first: pp. 1-14 DOI: $10.1111 /$ nous.12144

Wallis C. 2008. Consciousness, context, and know-how. Synthese 160(1): 123-153. DOI: 
10.1007/s11229-006-9103.3 